\title{
A temporal analysis of the spatial clustering of food outlets around schools in Christchurch, New Zealand, 1966 to 2006
}

\author{
Peter L Day ${ }^{1}$, Jamie R Pearce ${ }^{2}$ and Amber L Pearson ${ }^{3, *}$ \\ 'GeoHealth Laboratory, Department of Geography, University of Canterbury, Canterbury, New Zealand: \\ ${ }^{2}$ Centre for Research on Environment, Society \& Health (CRESH), School of GeoSciences, University of \\ Edinburgh, Edinburgh, UK: ${ }^{3}$ Department of Public Health, University of Otago, 23A Mein Street, Newtown, \\ Wellington 6242, New Zealand
}

Submitted 4 February 2013: Final revision received 11 September 2013: Accepted 17 September 2013: First published online 6 November 2013

\begin{abstract}
Objective: To explore changes in urban food environments near schools, as potential contributors to the rising prevalence of overweight and obesity among children.

Design: Addresses of food premises and schools in 1966, 1976, 1986, 1996 and 2006 were geo-coded. For each year, the number and proportion of outlets by category (supermarket/grocery; convenience; fast-food outlet) within $800 \mathrm{~m}$ of schools were calculated. The degree of spatial clustering of outlets was assessed using a bivariate K-function analysis. Food outlet categories, school level and school social deprivation quintiles were compared.

Setting: Christchurch, New Zealand.

Subjects: All schools and food outlets at 10-year snapshots from 1966 to 2006.

Results: Between 1966 and 2006, the median number of supermarkets/grocery stores within $800 \mathrm{~m}$ of schools decreased from 5 to 1, convenience stores decreased from 2 to 1 , and fast-food outlets increased from 1 to 4 . The ratio of fast-food outlets to total outlets increased from $0 \cdot 10$ to $0 \cdot 67$. The clustering of fastfood outlets was greatest within $800 \mathrm{~m}$ of schools and around the most socially deprived schools. Over the 40-year study period, school food environments in Christchurch can be characterized by increased densities of fast-food outlets within walking distance of schools, especially around the most deprived schools. Conclusions: Since the 1960s, there have been substantial changes to the food environments around schools which may increasingly facilitate away-from-home food consumption for children and provide easily accessible, cheap energydense foods, a recognized contributor to the rise in prevalence of overweight and obesity among young people.
\end{abstract}

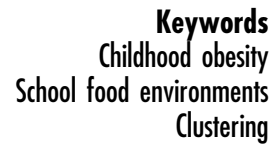

Clustering
Obesity is a major risk factor for numerous chronic health conditions such as type 2 diabetes, heart disease, high blood pressure and stroke, various types of cancer, and a number of psychological and social problems ${ }^{(1)}$. The rapid rise in the prevalence of both overweight and obesity for adults and children over the past decades has placed a considerable burden upon the health systems of many nations ${ }^{(2)}$. In fact, the estimated worldwide prevalence of childhood overweight and obesity increased from $4 \cdot 2 \%$ in 1990 to $6.7 \%$ in 2010 and is expected to reach $9 \cdot 1 \%$ by $2020^{(3)}$. Trends in New Zealand are similar, where one in twelve children (aged 2 to 14 years) is obese and one in five is overweight ${ }^{(4)}$. Numerous studies suggest that obese children are more likely to be obese into adulthood ${ }^{(5)}$.

Explanations for the rapid rise in child obesity are wideranging but the influence of environmental factors has drawn particular attention ${ }^{(6)}$. The emergence of 'obesogenic food environments' has been posited as a key driver ${ }^{(7,8)}$. Without doubt, a complex relationship between food environments and obesity exists, and various models of food systems and behaviours have been proposed ${ }^{(9)}$. These include access and availability of either healthy or unhealthy food options near schools and worksites ${ }^{(10)}$ and the proliferation of cheap, energy-dense foods available from convenience outlets and fast-food venues. A number of studies have provided evidence of a link between the available food options and overweight and obesity ${ }^{(11-16)}$. Another factor is the rise in food consumption away from home, which has also been found to have contributed to the prevalence of overweight and obesity ${ }^{(17)}$. Estimates suggest that increased energy intake alone is more than sufficient to explain the weight gain in the US population since the 1970 s and for women in the UK since the $1980 \mathrm{~s}^{(18,19)}$ 
Schools are an important feature of local food environments for children and adolescents as they provide a number of eating options for those enrolled, such as in-school cafeterias, vending machines and nearby food outlets. However, studies examining the influence of school food environments on the dietary behaviour and health of children are contradictory. For example, a study in California found that students were more likely to be overweight or obese if there was a fast-food outlet within 0.5 mile of their school ${ }^{(20)}$ while another study in the USA found that fast-food outlets within $0 \cdot 1$ mile of school was associated with a $5 \cdot 2 \%$ increase in obesity rates among high-school children, whereas there was not a noticeable effect at greater distances ${ }^{(21)}$. However, other studies have found little evidence of an association between proximity of outlets to schools and health outcomes ${ }^{(22,23)}$.

Geospatial technologies such as Geographic Information Systems (GIS) have proved to be valuable tools in assessing local food environments. Most often the technology is used to determine the proximity of food outlets to schools using either density- or distance-based measures $^{(20,24-30)}$. The consensus from this growing body of work is that fast-food and/or convenience stores are most often located within close proximity to schools, giving pupils ready access to obesity-promoting foods. A Chicago-based study found that there were far greater numbers of fast-food outlets located within a $1.5 \mathrm{~km}$ radius of schools compared with the numbers that might be expected by chance ${ }^{(29)}$. Moreover, the densities of fastfood and convenience stores around schools have been found to vary according to neighbourhood income and ethnic composition ${ }^{(25-28,30)}$. For example, a study of five large urban areas across New Zealand found a significant clustering of fast-food and convenience stores near more deprived schools and schools in areas of high population density and commercial land use ${ }^{(30)}$.

In a number of countries, including the USA, the UK and New Zealand, the structure and mix of urban food retailing over the past 30 years have changed, with a decline in small grocery stores and increases in large supermarkets, fast-food outlets, cafés and restaurants. The impact of these changes on dietary behaviour and related health outcomes is largely unclear but a small number of longitudinal studies have been undertaken. These include a study of the foodscape in Northumbria in the north-east of England that found no association between food intake and the rapid increases in food outlets between 1980 and 2000 in the area. There was however some evidence of a link between the local school environments in 1980 and changes in BMI over the study period ${ }^{(31)}$. In the USA, another study found that over a 15 -year period, fast-food consumption was linked with availability within $3 \mathrm{~km}$ of home for low-income males, while the relationships between grocery store availability and diet were mixed ${ }^{(32)}$. Examination of the longitudinal changes in school food environments provides some insight into the extent to which these environments have come to be dominated by outlets selling unhealthy foods, and the potential for these environments to create, maintain and exacerbate inequalities in obesity and contribute to the coinciding increase in the prevalence of overweight and obesity in children.

Building on previous work, in the present study we examine changes in the food environments around schools over a 40-year period in a large urban area of New Zealand.

\section{Methods}

\section{Data}

The New Zealand Ministry of Education provided the addresses of schools located in Christchurch in 2006. Each school was classified as either primary/intermediate (Years 1-8), middle (Years 1-15) or secondary (Years 7-15). The location of schools for earlier years (i.e. 1966, 1976, 1986 and 1996) was obtained from telephone directories and verified by Internet sources. Food outlet data for 2006 were sourced from the Christchurch City Council which licenses food outlets and from telephone directories for earlier years. The 2006 data included food license categories such as 'Grocery' or 'Takeaway foods' or business trading name with identifying information such as 'Fish 'n' chips' or 'Dairy' (a colloquial term for a convenience store). For earlier years, we systematically searched the Yellow Pages business telephone directory using classifications such as 'Foods - takeaway', 'Grocery Stores' or 'Dairies' and the business trading name to identify food outlets for the analysis. This data collection approach was verified in earlier food outlet studies ${ }^{(33,34)}$. In order to measure changes over time, food outlets were assigned a category, i.e. those selling: (i) a wide range of foods (supermarkets/grocery stores), (ii) a more limited range of foods including 'dairies' and small fruit and vegetable shops (convenience) and (iii) predominantly unhealthy foods (fast-food outlets).

A measure of the school's deprivation was derived for each school in each study year. The measure was based on the 2006 New Zealand Ministry of Education school socio-economic status deciles ${ }^{(35)}$, converted to quintiles $(1=$ least deprived, $5=$ most deprived $)$. School socioeconomic status quintiles in years prior to 2006 were estimated using an average of the weighted neighbourhood deprivation measure for each school based on its catchment area. A $2 \mathrm{~km}$ Euclidean buffer was created around each school and these were overlaid with 1991 Census Area Unit boundaries ( $n$ 106), the earliest year for which digital boundaries were available. Each Census Area Unit was assigned a measure of deprivation, which was then weighted by population. For the years 1996 and 1986, the New Zealand Index of Deprivation (NZDep) was used (note: the 1991 NZDep was used in 1986, as this was the first year the index was available) ${ }^{(36)}$. For the 
years 1976 and 1966, a Census proxy measure of deprivation was used (quintiles of the proportion of professional employees of all employees, where $1=$ high proportion, $5=$ low proportion). The use of proportions of professional workers as a proxy for deprivation has been validated previously, with correlations between the proxy and NZDep of $0.50-0.58$ over the study period ${ }^{(33)}$.

\section{Analysis}

Using GIS, the median number of food outlets located within an $800 \mathrm{~m}$ Euclidean buffer (approximately 10-min walking time) of each school was calculated. The analysis was stratified by food outlet category, school level and school deprivation quintile. The ratio of each category of food outlet to total outlets within $800 \mathrm{~m}$ of schools was also calculated.

The spatial clustering of food outlets within $1600 \mathrm{~m}$ of each school (school catchments) was determined using a bivariate K-function analysis ${ }^{(30)}$. The K-function estimates the expected number of random points of food outlet types within a given distance of a school divided by the average number of points by outlet type in the area. This expected K-function distribution was compared with the observed distribution in a ratio. Ratios close to or less than 1.0 indicated that the observed spatial pattern was similar to a random pattern, whereas ratios greater than 1.0 indicate spatial clustering. The geographic area for the cluster analysis was restricted to $1600 \mathrm{~m}$ in order to capture catchment areas around each school. In cluster analyses, food outlet categories and high deprived $v$. low deprived schools were compared. We used the software packages IBM SPSS Statistics version 19 to undertake the descriptive analysis, ArcGIS 10 (ESRI, Redlands, CA, USA) for the GIS analysis, and the Spatstat package in $\mathrm{R} \mathrm{v2} \cdot 10 \cdot 0$ for the statistical analysis of spatial point pattern analysis.

\section{Results}

The population of Christchurch increased from about 300000 in 1966 to approximately 362000 in 2006 (Table 1). Of the schools that were in operation in 1966 ( $n$ 116), sixty-five remained in the same deprivation quintile throughout the entire study period, while fifteen were in a more deprived quintile ranking and fifteen were in a less deprived quintile ranking by the end of the study period. All but two schools shifted by a maximum of one quintile over time. The numbers of large and small food retailers in Christchurch changed considerably over the 40-year study period. For example, current large supermarket chains such as 'New World', 'Countdown', 'Pak 'n' Save' and 'Fresh Choice' which retail an extensive range of food have replaced numerous smaller 'superettes' such as 'IGA' and 'Four Square'. These latter chain stores typically sold more limited food options in earlier years. Fast-food outlets in the 1960s comprised mostly of fish retailers/fish and chip shops but in later years expanded to include multinational fast-food chain stores such as Kentucky Fried Chicken, McDonalds and Pizza Hut. Numerous other locally operated takeaway food outlets serving Indian, Chinese and Thai meals also grew rapidly during

Table 1 Number of schools, food outlets and population, Christchurch, New Zealand, 1966-2006

\begin{tabular}{|c|c|c|c|}
\hline \multicolumn{4}{|c|}{ Schools within the Christchurch Metropolitan Area } \\
\hline Year & Primary/intermediate & Secondary & Total \\
\hline 1966 & 92 & 24 & 116 \\
\hline 1976 & 107 & 26 & 133 \\
\hline 1986 & 108 & 27 & 135 \\
\hline 1996 & 109 & 29 & 138 \\
\hline 2006 & 111 & 31 & 142 \\
\hline
\end{tabular}

Food outlets within the Christchurch Metropolitan Area

\begin{tabular}{lcccc}
\hline Year & Supermarkets/grocery stores & Fast-food outlets & Convenience/fruit \& vegetable stores & Total \\
\hline 1966 & 375 & 65 & 185 & 163 \\
1976 & 171 & 117 & 203 & 451 \\
1986 & 122 & 247 & 163 & 572 \\
1996 & 61 & 271 & 119 & 495 \\
2006 & 62 & 349 & 530
\end{tabular}

Population within the Christchurch Metropolitan Area

\begin{tabular}{lccc}
\hline Year & Total & 5-19 years of age & \% of population 5-19 years old \\
\hline 1966 & 277733 & 79154 & $28 \cdot 5$ \\
1976 & 286472 & 81045 & $28 \cdot 3$ \\
1986 & 293833 & 69809 & $23 \cdot 8$ \\
1996 & 325250 & 65690 & $20 \cdot 2$ \\
2006 & 361800 & 71310 & $19 \cdot 7$ \\
\hline
\end{tabular}

Source: Statistics New Zealand Subnational Population Estimates. 
Table 2 Median number of food outlets within $800 \mathrm{~m}$ by school type and deprivation quintile, Christchurch, New Zealand, 1966-2006

\begin{tabular}{|c|c|c|c|c|c|c|c|c|c|}
\hline \multirow[b]{2}{*}{ Food outlet category and year } & \multirow{2}{*}{$\begin{array}{c}\text { All } \\
\text { schools }\end{array}$} & \multirow{2}{*}{$\begin{array}{l}\text { Primary } \\
\text { schools* }\end{array}$} & \multirow{2}{*}{$\begin{array}{l}\text { Secondary } \\
\text { schoolst }\end{array}$} & \multicolumn{5}{|c|}{ School deprivation quintile ( $1=$ low, $5=$ high $)$} & \multirow[b]{2}{*}{ Ratio Q5:Q1 } \\
\hline & & & & 1 & 2 & 3 & 4 & 5 & \\
\hline \multicolumn{10}{|l|}{ Supermarkets/grocery stores } \\
\hline 1966 & 5 & 5 & 6 & 3 & 6 & 6 & 5 & 8 & $2 \cdot 7$ \\
\hline 1976 & 2 & 2 & 3 & 2 & 3 & 3 & 2 & 3 & 1.5 \\
\hline 1986 & 2 & 2 & 2 & 2 & 2 & 1 & 2 & 2 & $1 \cdot 0$ \\
\hline 1996 & 1 & 1 & 1 & 1 & 1 & 1 & 1 & 1 & $1 \cdot 0$ \\
\hline 2006 & 1 & 1 & 1 & 1 & 1 & 1 & 0 & 1 & $1 \cdot 0$ \\
\hline \multicolumn{10}{|l|}{ Fast-food outlets } \\
\hline 1966 & 1 & 1 & 1 & 1 & 1 & 1 & 1 & 1 & $1 \cdot 0$ \\
\hline 1976 & 1 & 1 & 2 & 1 & 1 & 1 & 2 & 2 & $1 \cdot 5$ \\
\hline 1986 & 3 & 2 & 5 & 2 & 2 & 2 & 4 & 3 & 1.5 \\
\hline 1996 & 3 & 3 & 3 & 1 & 3 & 3 & 3 & 4 & $4 \cdot 0$ \\
\hline 2006 & 4 & 4 & 5 & 3 & 4 & 5 & 5 & 7 & $2 \cdot 3$ \\
\hline \multicolumn{10}{|c|}{ Convenience/fruit \& vegetable stores } \\
\hline 1966 & 2 & 2 & 3 & 2 & 3 & 3 & 2 & 3 & 1.5 \\
\hline 1976 & 2 & 2 & 2 & 1 & 3 & 2 & 2 & 2 & $2 \cdot 0$ \\
\hline 1986 & 3 & 3 & 3 & 2 & 3 & 3 & 3 & 4 & $2 \cdot 0$ \\
\hline 1996 & 2 & 2 & 2 & 1 & 2 & 2 & 3 & 3 & $3 \cdot 0$ \\
\hline 2006 & 1 & 2 & 1 & 1 & 1 & 1 & 2 & 2 & $2 \cdot 0$ \\
\hline \multicolumn{10}{|l|}{ Total food outlets of these types } \\
\hline 1966 & 9 & 8 & 11 & 6 & 9 & 11 & 7 & 12 & $2 \cdot 0$ \\
\hline 1976 & 6 & 6 & 8 & 6 & 8 & 5 & 6 & 7 & $1 \cdot 3$ \\
\hline 1986 & 7 & 7 & 11 & 4 & 8 & 6 & 8 & 10 & $2 \cdot 5$ \\
\hline 1996 & 6 & 5 & 7 & 3 & 7 & 6 & 6 & 9 & $3 \cdot 0$ \\
\hline 2006 & 6 & 6 & 6 & 4 & 6 & 6 & 7 & 10 & $2 \cdot 5$ \\
\hline
\end{tabular}

*Includes intermediate schools.

tIncludes middle schools.

this period. The number of small convenience stores typically offering a smaller range of convenience and fresh foods has remained largely unchanged throughout the period.

The median number of food outlets within $800 \mathrm{~m}$ of schools decreased from 9 in 1966 to 6 in 2006; grocery stores and supermarkets decreased from 5 to 1 ; fast-food outlets increased from 1 to 4; and convenience stores decreased from 2 to 1 (Table 2). There was little difference between school primary and secondary levels in terms of food outlet presence, except for an increase in the number of fast-food outlets around secondary schools where the median number increased from 1 to 5 . In each year, the median number of fast-food outlets within $800 \mathrm{~m}$ of schools increased more rapidly around the more deprived schools compared with the least deprived schools. The median number of fast-food outlets around the most deprived schools increased from 1 in 1966 to 7 in 2006 compared with an increase from 1 to 3 outlets around the least deprived schools. The median number of convenience and fruit and vegetable outlets near the most deprived schools increased slightly and remained consistently higher. Overall the median number of supermarkets/grocery stores decreased markedly over time near schools but the numbers remained similar across the deprivation quintiles. The median ratios of supermarkets/grocery stores to total outlets within $800 \mathrm{~m}$ from schools decreased from 0.61 in 1966 to $0 \cdot 10$ in 2006 (Fig. 1). Conversely, for fast-food outlets the ratio increased over the study period (from $0 \cdot 10$ to $0 \cdot 67$ ) and for convenience and fruit and vegetable stores the values remained fairly constant $(0 \cdot 28$ to $0 \cdot 25)$.

The spatial clustering of food outlets around schools was evident for all three categories of outlets, in each year of the study period (Table 3). There was little difference in the magnitude of clustering between food outlet categories at the specified distances from schools over the years. However, the ratios were consistently greater at distances of $800 \mathrm{~m}$ or less compared with greater distances, indicating that clustering was stronger within walking distances of schools. Ratios at $800 \mathrm{~m}$ distance from schools ranged from $2 \cdot 0$ to $2 \cdot 3$ for supermarkets/ grocery stores, from 1.9 to $2 \cdot 3$ for fast-food outlets and from 1.8 to $2 \cdot 4$ for convenience stores; while at $1600 \mathrm{~m}$ from schools, ranges of ratios were $1 \cdot 6-1 \cdot 8,1 \cdot 6-1 \cdot 8$ and $1 \cdot 7-1 \cdot 9$, respectively.

In comparing clustering of outlets by school deprivation level, the most socially deprived schools had consistently higher ratios across all distances compared with the least deprived, which indicates that clustering was stronger around the most deprived schools (Table 4). For all outlet types and each year, the largest ratio differences were found for distances of $800 \mathrm{~m}$ or less from schools.

\section{Discussion}

The results of the present work suggest that the availability of energy-dense foods, such as those found at 

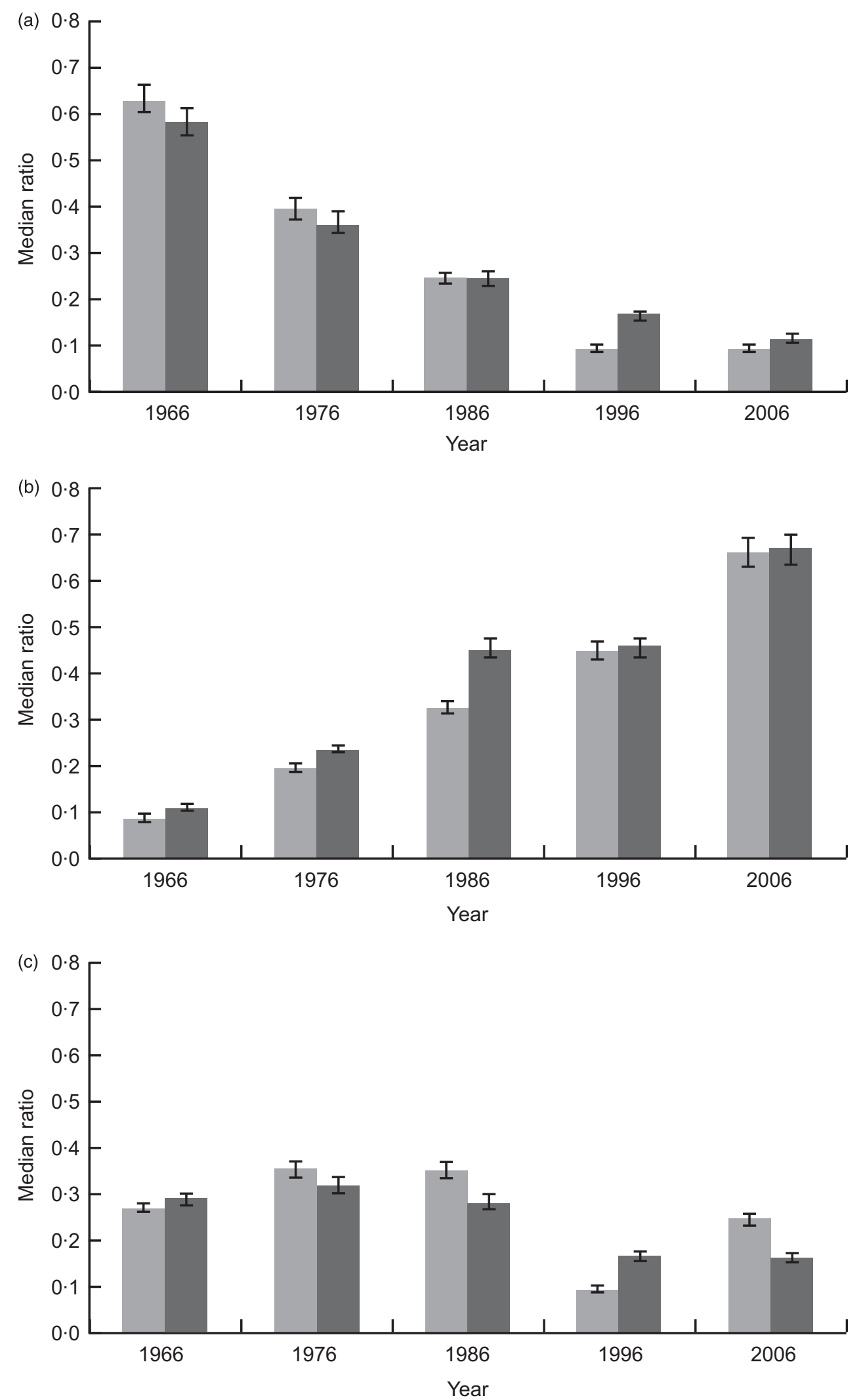

Fig. 1 Ratio of the number of (a) supermarkets/grocery stores, (b) fast-food outlets and (c) convenience/fruit and vegetable stores to total food outlets within $800 \mathrm{~m}$ of schools ( $\square$, primary schools; $\square$, secondary schools), Christchurch, New Zealand, 1966-2006. Values are medians, with their $95 \%$ confidence intervals represented by vertical bars 
Table 3 Ratios and $95 \%$ confidence intervals of observed to expected K-function outlet densities at distances from schools, Christchurch, New Zealand, 1966-2006

\begin{tabular}{|c|c|c|c|c|c|c|c|c|}
\hline \multirow[b]{3}{*}{ Food outlet category and year } & \multicolumn{8}{|c|}{ Distance from all schools } \\
\hline & \multicolumn{2}{|c|}{$400 \mathrm{~m}$} & \multicolumn{2}{|c|}{$800 \mathrm{~m}$} & \multicolumn{2}{|c|}{$1200 \mathrm{~m}$} & \multicolumn{2}{|c|}{$1600 \mathrm{~m}$} \\
\hline & Ratio & $95 \% \mathrm{Cl}$ & Ratio & $95 \% \mathrm{Cl}$ & Ratio & $95 \% \mathrm{Cl}$ & Ratio & $95 \% \mathrm{Cl}$ \\
\hline \multicolumn{9}{|l|}{ Supermarkets/grocery stores } \\
\hline 1966 & $2 \cdot 2$ & $1 \cdot 8,2 \cdot 5$ & $2 \cdot 0$ & $1 \cdot 8,2 \cdot 2$ & 1.9 & $1 \cdot 7,2 \cdot 0$ & $1 \cdot 8$ & $1 \cdot 7,1 \cdot 9$ \\
\hline 1976 & $2 \cdot 3$ & $2 \cdot 1,2 \cdot 4$ & $2 \cdot 3$ & $1 \cdot 9,2 \cdot 1$ & $1 \cdot 8$ & $1 \cdot 8,1 \cdot 9$ & $1 \cdot 7$ & $1 \cdot 7,1 \cdot 8$ \\
\hline 1986 & $2 \cdot 2$ & $1 \cdot 9,2 \cdot 6$ & $2 \cdot 2$ & $2 \cdot 0,2 \cdot 3$ & $1 \cdot 8$ & $1 \cdot 7,2 \cdot 0$ & $1 \cdot 7$ & $1 \cdot 6,1 \cdot 8$ \\
\hline 1996 & $1 \cdot 8$ & $1 \cdot 3,2 \cdot 4$ & $2 \cdot 0$ & $1 \cdot 7,2 \cdot 3$ & $1 \cdot 8$ & $1 \cdot 6,2 \cdot 0$ & $1 \cdot 6$ & $1 \cdot 5,1 \cdot 8$ \\
\hline 2006 & $2 \cdot 1$ & $0 \cdot 4,3 \cdot 8$ & $2 \cdot 2$ & $1 \cdot 4,3 \cdot 1$ & $2 \cdot 1$ & $1 \cdot 5,2 \cdot 7$ & $1 \cdot 8$ & $1 \cdot 4,2 \cdot 3$ \\
\hline \multicolumn{9}{|l|}{ Fish shops/fast-food outlets } \\
\hline 1966 & $2 \cdot 5$ & $2 \cdot 4,2 \cdot 6$ & $2 \cdot 2$ & $2 \cdot 1,2 \cdot 2$ & $1 \cdot 9$ & $1 \cdot 9,2 \cdot 0$ & $1 \cdot 8$ & $1 \cdot 8,1 \cdot 9$ \\
\hline 1976 & $2 \cdot 3$ & $2 \cdot 2,2 \cdot 3$ & $2 \cdot 3$ & $2 \cdot 0,2 \cdot 1$ & $1 \cdot 8$ & $1 \cdot 8,1 \cdot 8$ & $1 \cdot 8$ & $1 \cdot 7,1 \cdot 8$ \\
\hline 1986 & $2 \cdot 1$ & $2 \cdot 0,2 \cdot 1$ & $2 \cdot 1$ & $2 \cdot 1,2 \cdot 1$ & $1 \cdot 8$ & $1 \cdot 8,1 \cdot 9$ & $1 \cdot 8$ & $1 \cdot 7,1 \cdot 8$ \\
\hline 1996 & $2 \cdot 1$ & $2 \cdot 0,2 \cdot 1$ & 1.9 & $1 \cdot 8,1 \cdot 9$ & $1 \cdot 7$ & $1 \cdot 7,1 \cdot 7$ & $1 \cdot 6$ & $1 \cdot 6,1 \cdot 7$ \\
\hline 2006 & $2 \cdot 4$ & $1 \cdot 6,3 \cdot 3$ & $2 \cdot 2$ & $1 \cdot 8,2 \cdot 6$ & 1.9 & $1 \cdot 6,2 \cdot 2$ & $1 \cdot 8$ & $1 \cdot 6,2 \cdot 0$ \\
\hline \multicolumn{9}{|c|}{ Convenience/fruit \& vegetable stores } \\
\hline 1966 & $2 \cdot 3$ & $2 \cdot 3,2 \cdot 4$ & $2 \cdot 0$ & $2 \cdot 0,2 \cdot 1$ & $2 \cdot 0$ & $1 \cdot 9,2 \cdot 0$ & 1.9 & $1 \cdot 9,1.9$ \\
\hline 1976 & $2 \cdot 4$ & $2 \cdot 2,2 \cdot 5$ & $2 \cdot 4$ & $2 \cdot 0,2 \cdot 1$ & $1 \cdot 9$ & $1 \cdot 8,1 \cdot 9$ & $1 \cdot 8$ & $1 \cdot 8,1 \cdot 8$ \\
\hline 1986 & $2 \cdot 5$ & $2 \cdot 3,2 \cdot 6$ & $2 \cdot 0$ & $2 \cdot 0,2 \cdot 1$ & $1 \cdot 8$ & $1 \cdot 8,1 \cdot 9$ & $1 \cdot 8$ & $1 \cdot 7,1 \cdot 8$ \\
\hline 1996 & $2 \cdot 3$ & $2 \cdot 2,2 \cdot 4$ & $1 \cdot 8$ & $1 \cdot 8,1 \cdot 9$ & $1 \cdot 7$ & $1 \cdot 7,1 \cdot 7$ & $1 \cdot 7$ & $1 \cdot 6,1 \cdot 7$ \\
\hline 2006 & $2 \cdot 3$ & $2 \cdot 2,2 \cdot 4$ & $2 \cdot 0$ & $1 \cdot 9,2 \cdot 1$ & $1 \cdot 8$ & $1 \cdot 8,1 \cdot 9$ & $1 \cdot 7$ & $1 \cdot 7,1 \cdot 8$ \\
\hline
\end{tabular}

fast-food outlets, in close proximity to schools could be an important driver for the increasing prevalence of overweight and obesity in children in the country. This result is not new as the obesogenic nature of food environments around schools has been consistently noted in many international studies ${ }^{(20,25-30)}$. The results of the current New Zealand-based study add to this extant literature however by providing an important longitudinal perspective to research of this nature ${ }^{(37)}$. Moreover, we demonstrated that the retail mix of food outlets within close proximity of schools has changed markedly since the 1960s with a large reduction in the availability of supermarkets/grocery stores, a small decrease in convenience stores and a large increase in fast-food outlets near schools. The patterns of spatial clustering were similar between all food outlet categories across all study years but were greatest within walking distance $(800 \mathrm{~m})$ of schools. These trends were particularly evident for the most deprived schools, where the degree of spatial clustering was at least twice that of the least deprived schools. There was also a clear social gradient in food outlet type distribution and clustering around schools, with higher densities of fast-food and convenience stores around the most deprived schools, which has previously been identified in a US-based study ${ }^{(29)}$.

The mechanisms that might explain these findings are myriad but could include explanations pertaining to consumer demand generated from high population densities, land-use zoning measures, co-location of other businesses, land prices and rental costs ${ }^{(30,34,38)}$. Historic land-use practices may also have influenced the co-location of schools and food retail outlets more generally.
Population growth within Christchurch and the building of nine new schools over the 40-year study period has paralleled the development of a retail food base around schools. The increase in the number of fast-food outlets around schools may indicate the development of obesogenic environments which have emerged around schools. The extent to which schools have been targeted by the fast-food industry is unknown. However, a large school pupil consumer base is likely to be an important consideration in this regard.

The study has a number of limitations. First, deprivation data about schools prior to 2006 were not available, so proxy measures were used to derive school deprivation for earlier years. Second, we were unable to fully verify historical food outlet and school data as we relied upon telephone directories and, where available, Internet sources. In addition, the categorization of these outlets did not involve a review of all items sold in these outlets. Third, digitized road networks were not available over the study period, so it was not possible to derive buffers or school catchments using road distance or to undertake a road network-based K-function analysis. Since the standard K-function methodology relies upon a planar space assumption of straight-line distance between points, this could lead to the over-detection of clustered patterns in road network-constrained school and food outlet points ${ }^{(39-41)}$. Last, our study did not consider whether food environments around schools influence student diet, food purchasing behaviour or related health outcomes. Future studies could investigate the temporal dynamics of food environment risk and the effects on diet and health outcomes over the life course from youth to adulthood. Considering residential movement and potential differences across urban/rural 
communities and within socio-economic and ethnic subpopulations would also be of value $e^{(42)}$.

\section{Conclusions}

The present study adds an important longitudinal component to the burgeoning work on school food environments. We found a number of obesity-promoting features of these environments and the potential for these environments to create or exacerbate inequalities in obesity. Specifically, we observed an evolution in Christchurch from supermarkets/ grocery stores to fast-food outlets and strong spatial clustering of these outlets around more socially deprived schools. Childhood exposure to negative food environments has important implications for obesity risk in childhood. Consideration should be given to enhancing food environments including environmental-level interventions that improve the food choices available to children around schools. Following the significant earthquakes, notably the most damaging event on 22 February 2011 which caused many fatalities and extensive infrastructural damage, Christchurch faces unprecedented opportunities for reconsidering the spatial arrangement of the urban built environment, including food environments. Many older unreinforced masonry buildings in commercial centres have had to be demolished. These buildings were popular locations for fast-food and convenience outlets. Draft planning and public consultations for the rebuilding of the central city and suburban commercial centres is currently in process ${ }^{(43)}$ and it is anticipated that this type of policy/zoning intervention could enforce much needed change similar to those in Buffalo, New York, where a proposed ban on tobacco sales within 1000 feet of schools or at facilities frequented by youth (e.g. movie theatres, bowling alleys, etc.) has been supported in principle by the council $^{(44)}$. It is important to ensure that the reconstructed built environment in Christchurch supports public health concerns including healthy eating for children.

\section{Acknowledgements}

Sources of funding: P.L.D. and A.L.P. were funded through the GeoHealth Laboratory (New Zealand Ministry of Health). J.R.P. is supported by the European Research Council (ERC-2010-StG Grant 263501). The New Zealand Ministry of Health and the European Research Council had no role in the design, analysis or writing of this article. Conflicts of interest: There are no conflicts of interest. Ethical approval: No ethical approval was required for this research. Authors' contributions: P.L.D. and J.R.P. designed the study and drafted the manuscript. P.L.D. compiled and analysed the data. A.L.P. conducted further analyses and revised the manuscript. Acknowledgements: The authors wish to thank Dr Gregory Breetzke for his helpful comments on this paper. 


\section{References}

1. World Health Organization (2006) Obesity and overweight. http://www.who.int/mediacentre/factsheets/fs311/en/index. html (accessed March 2012).

2. Kelly T, Yang W, Chen CS et al. (2008) Global burden of obesity in 2005 and projections to 2030. Int J Obes (Lond) 32, 1431-1437.

3. de Onis M, Blössner M \& Borghi E (2010) Global prevalence and trends of overweight and obesity among preschool children. Am J Clin Nutr 92, 1257-1265.

4. Ministry of Health (2008) A Portrait of Health: Key Results of the 2006/07 New Zealand Health Survey. Wellington: Ministry of Health.

5. Suchindran C, North KE, Popkin BM et al. (2010) Association of adolescent obesity with risk of severe obesity in adulthood. JAMA 304, 2042-2047.

6. Pearce J \& Witten K (2010) Geographies of Obesity: Environmental Understandings of the Obesity Epidemic. Farnham, UK: Ashgate.

7. Swinburn B, Egger G \& Raza F (1999) Dissecting obesogenic environments: the development and application of a framework for identifying and prioritizing environmental interventions for obesity. Prev Med 29, 563-570.

8. Lake A \& Townshend T (2006) Obesogenic environments: exploring the built and food environments. J R Soc Promot Health 126, 262-267.

9. Story M, Kaphingst KM, Robinson-O'Brien R et al. (2008) Creating healthy food and eating environments: policy and environmental approaches. Annu Rev Public Health 29, 253-272.

10. McKinnon RA, Reedy J, Morrissette MA et al. (2009) Measures of the food environment. A compilation of the literature, 1990-2007. A J Prev Med 36, 4 Suppl., S124-S133.

11. Block J, Scribner R \& DeSalvo K (2004) Fast food, race/ ethnicity, and income: a geographic analysis. Am J Prev Med 27, 211-217.

12. Cummins SCJ, McKay L \& MacIntyre S (2005) McDonald's restaurants and neighborhood deprivation in Scotland and England. Am J Prev Med 29, 308-310.

13. Kwate NOA, Yau CY, Loh JM et al. (2009) Inequality in obesigenic environments: fast food density in New York City. Health Place 15, 364-373.

14. Larson NI, Story MT \& Nelson MC (2009) Neighborhood environments. Disparities in access to healthy foods in the US. Am J Prev Med 36, 74-81.

15. Morland K, Wing S, Diez Roux A et al. (2002) Neighborhood characteristics associated with the location of food stores and food service places. Am J Prev Med 22, 23-29.

16. Morland KB \& Evenson KR (2009) Obesity prevalence and the local food environment. Health Place 15, 491-495.

17. Swinburn B (2009) Obesity prevention in children and adolescents. Child Adolesc Psychiatr Clin N Am 18, 209-223.

18. Swinburn B, Sacks G \& Ravussin E (2009) Increased food energy supply is more than sufficient to explain the US epidemic of obesity. Am J Clin Nutr 90, 1453-1456.

19. Scarborough P, Burg MR, Foster C et al. (2011) Increased energy intake entirely accounts for increase in body weight in women but not in men in the UK between 1986 and 2000. Br J Nutr 105, 1399-1404.

20. Davis B \& Carpenter C (2009) Proximity of fast-food restaurants to schools and adolescent obesity. Am J Public Health 99, 505-510.

21. Currie J, Della Vigna S, Morettu E et al. (2009) The Effect of Fast Food Restaurants on Obesity and Weight Gain. Working Paper no. 14721. Cambridge, MA: National Bureau of Economic Research.

22. Timperio AF, Ball K, Roberts R et al. (2009) Children's takeaway and fast-food intakes: associations with the neighbourhood food environment. Public Health Nutr 12, 1960-1964.

23. van der Horst K, Timperio A, Crawford D et al. (2008) The school food environment. Associations with adolescent soft drink and snack consumption. Am J Prev Med 35, 217-223.

24. Charreire H, Casey R, Salze P et al. (2010) Measuring the food environment using geographical information systems: a methodological review. Public Health Nutr 13, 1773-1785.

25. Kestens Y \& Daniel M (2010) Social inequalities in food exposure around schools in an urban area. Am J Prev Med 39, 33-40.

26. Simon PA, Kwan D, Angelescu A et al. (2008) Proximity of fast food restaurants to schools: do neighborhood income and type of school matter? Prev Med 47, 284-288.

27. Sturm R (2008) Disparities in the food environment surrounding US middle and high schools. Public Health 122, 681-690.

28. Zenk SN \& Powell LM (2008) US secondary schools and food outlets. Health Place 14, 336-346.

29. Austin SB, Melly SJ, Sanchez BN et al. (2005) Clustering of fast-food restaurants around schools: a novel application of spatial statistics to the study of food environments. Am J Public Health 95, 1575-1581.

30. Day PL \& Pearce J (2011) Obesity-promoting food environments and the spatial clustering of food outlets around schools. Am J Prev Med 40, 113-121.

31. Burgoine T, Lake AA, Stamp E et al. (2009) Changing foodscapes 1980-2000, using the ASH30 Study. Appetite 53, $157-165$.

32. Boone-Heinonen J, Gordon-Larsen P, Kiefe CI et al. (2011) Fast food restaurants and food stores: longitudinal associations with diet in young to middle-aged adults: the CARDIA study. Arch Intern Med 171, 1162.

33. Pearce J \& Day P (2010) Neighbourhood histories and health: social deprivation and food retailing in Christchurch, New Zealand, 1966-2005. In Obesogenic Environments: Complexities, Perceptions and Objective Measures, pp. 183-198 [AA Lake, TG Townshend and S Alvanides, editors]. Chichester: Wiley-Blackwell.

34. Pearce J, Day P \& Witten K (2008) Neighbourhood provision of food and alcohol retailing and social deprivation in Urban New Zealand. Urban Policy Res 26, 213-227.

35. Ministry of Education (2008) How the decile is calculated. http://www.minedu.govt.nz (accessed January 2012).

36. Salmond C, Crampton P \& Atkinson J (2007) NZDep2006 Index of Deprivation. Wellington: Department of Public Health, University of Otago.

37. Law C, Power C, Graham H et al. (2007) Obesity and health inequalities. Obes Rev 8, 19-22.

38. Pearce J, Blakely T, Witten K et al. (2007) Neighborhood deprivation and access to fast-food retailing. A national study. Am J Prev Med 32, 375-382.

39. Yamada I \& Thill JC (2004) Comparison of planar and network K-functions in traffic accident analysis. J Transport Geogr 12, 149-158.

40. Okabe A \& Yamada I (2001) The K-function method on a network and its computational implementation. Geogr Anal 33, 271-290.

41. Spielman S (2006) Appropriate use of the $\mathrm{K}$ function in urban environments. Am J Public Health 96, 205.

42. Boone-Heinonen J \& Gordon-Larsen P (2012) Obesogenic environments in youth: concepts and methods from a longitudinal national sample. Am J Prev Med 42, e37-e46.

43. Christchurch City Council (2011) Central City Plan: Draft Central City Recovery Plan for Ministerial Approval, December 2011. http://resources.ccc.govt.nz/files/CentralCityDecember 2011/FinalDraftPlan/FinaldraftCentralCityPlan.pdf (accessed December 2011).

44. Tilson M (2011) Reducing the Availability of Tobacco Products at Retail: Policy Analysis. Toronto: Non-Smokers' Rights Association. 